\title{
BELIEF AND PARTICIPATION WITH CliniCAL PHYSIOTHERAPISTS IN RESEARCH
}

\begin{abstract}
Research is a major tool in updating professional knowledge and discovering of new techniques. The relevance of research to Physiotherapy in this era of evidence-based practice cannot be over-emphasised. This survey was carried out to investigate: a) the level of participation of Kuwait based clinical physical therapists (CPTs) in research (b) their research beliefs and (c) factors enhancing or hindering their participation in research.

One hundred and five CPTs from seven Ministry of Health (MOH) Hospitals were surveyed, using a 21 - item structured questionnaire.

\author{
HAMZAT TK, \\ B.Sc. (Hons) Physiotherapy, \\ Ph.D, MNSP.; \\ AMUSAT NT,
}

B.sc (Hons) Physiotherapy, MN SP. ${ }^{2}$

1 Department of Physiotherapy, College of Medicine,

University of Ibadan. Ibadan, Nigeria.

Department of Physiotherapy,In-patient Unit,

Physical Medicine and Rehabilitaion Hospital, Kuwait. Ninety-six of the 105 questionnaire forms were returned, 87 (90.6\%) of which were complete. The results showed that 71 (81.6\%) of the participants agreed that CPTs should engage in research and 79 (90.8\%) believed that research would enhance practice. While 75 (86.2\%) claimed that reading Physiotherapy journals has enhanced their practice, only 34 (39.1\%) had ever participated in any research since qualifying as a basic physiotherapist. Only 6(6.9\%) had scientific publications in professional journals and 34 (39.1\%) were regularly subscribing to professional journals. Five factors were identified as hindrances to research. These were poor library facilities (80.4\%), time constraints (86.2\%), lack of research funds (74.7\%), lack of equipment $(71.3 \%)$ and lack of pre-requisite training in research activities (44.8\%).
\end{abstract}

From the results obtained in this survey, it can be inferred that the level of participation of Kuwait - based CPTs in research is very low. Thus, implying that clinical observations are not being validated through research. Acquisition of new knowledge and updating on existing/methods/techniques through the reading of professional Journals is low.

KEY WORDS: RESEARCH, PHYSIOTHERAPY, CLINICAL PHYSICAL THERAPISTS, BELIEF, ATTITUDE.

\section{INTRODUCTION}

Physiotherapy is rapidly evolving as a profession with distinct autonomy, identity and a knowledge base. Flourishing research activities are one reason for the observed feeling of autonomy and identity (Crosbie ,2000). It is therefore not surprising that research and its publication are increasingly emphasised, though these had long been realized

CORRESPONDENCE TO:

N.T Amusat

P.O. Box 6432,

Hawally.

Kuwait 32039.

Tel: 965-4892107,

Cell phone: 965-6097974

E-mail:sepet69@hotmail.com
(Fowler 1969, Rogers 1976, Basmajian 1977). Powers and Knapp (1995) have described research as a systematic process of investigation, with the purpose of contributing to the body of knowledge, that would shape and guide academic and / or clinical disciplines. Research can broadly be divided into basic and applied investigations. Basic research is intended to increase the understanding of the course of function being studied, while applied research may be referred to as clinical research or trials which are concerned with applying or gaining knowledge in practice (Currier, 1979). Research leads to revision of accepted conclusions in the light of newly discovered facts. Such findings should change practice accordingly (Smeitzer and Hindshaw, 1986). The total benefit of research comes when its findings are published in a scholarly journal. Though hand-to-hand transmission of research is possible, publications allows for critical review and prevent disreputable ad-hoc use (Parry, 1994).

It has been suggested that physical therapy clinicians do not participate in research like their academic counterparts. A situation that may be due to the fact that most clinical positions do not have research as part of their job descriptions (Crosbie, 2000), unlike academics who need research publications for career advancement. This argument however may be based on conjecture, as there is a dearth of information on the participation level of clinical and academic physical therapists in research activities, especially in Kuwait. This 
cross-sectional survey study was carried out to:

i) investigate the level of participation of Kuwait-based clinical physical therapists (CPTs) in research,

ii) study their beliefs about research; and

iii) identify factors that could be facilitating or hindering their participation in research activities.

\section{MATERIALS AND METHODS}

\section{Subjects:}

A convenient sample comprising all CPTs working in seven randomly selected Ministry of Health Hospitals and the Kuwait-Dalhousie Physiotherapy Center participated in the study. The hospitals were general and specialist clinical centres. The scientific committee of Kuwait's Office of Physiotherapy Affairs, approved the study.

\section{Materials:}

The instrument used for data collection was a 21 item structured close-ended questionnaire. The questionnaire, which was pilot-tested was divided into two segments. Section A sought demographic information about the respondents as well as information about their research and publication history. Section B comprised eleven close-ended statements aimed at seeking information on beliefs and attitude of respondents to research and factors hindering and or facilitating their participation in research studies. Respondents were asked to indicate their agreement or otherwise with the eleven statements, by checking "Agree" or "Disagree" as appropriate. The questionnaire forms were hand-distributed and collected by the second author (NTA). Only the completed forms were used for the data analysis. Data obtained were analysed using descriptive statistics.

\section{RESULTS}

A total of 96 out of 105 distributed questionnaire forms were retrieved and $87(90.6 \%)$ were completed by the respondents and included in the study. Forty-six $(52.8 \%)$ were Kuwaitis and the others $41(47.2 \%)$ were of different nationalities. Their years of experience ranged from 3 to 35 , with a median of 7

Table 1: Research Activities' Profile

\begin{tabular}{|l|c|c|c|c|}
\hline & \multicolumn{2}{|c|}{ Yes } & \multicolumn{2}{c|}{ No } \\
\hline & $\mathbf{n}$ & $\%$ & $\mathbf{n}$ & $\%$ \\
\hline $\begin{array}{l}\text { 1. Research training and dissertation at } \\
\text { undergraduate level }\end{array}$ & 36 & 41.4 & 51 & 58.6 \\
\hline 2. Post-basic research work & 34 & 39.1 & 53 & 60.9 \\
\hline $\begin{array}{l}\text { 3. Publication in professional journal } \\
\text { 4. Regular subscription in profession } \\
\text { journal }\end{array}$ & 6 & 6.9 & 81 & 93.1 \\
\hline $\begin{array}{l}\text { 5. Benefits from reading professional } \\
\text { journal }\end{array}$ & 75 & 39.1 & 53 & 60.9 \\
\hline
\end{tabular}

Table 2: Belief About Participation In Research

\begin{tabular}{|l|c|c|c|c|}
\hline & \multicolumn{2}{|c|}{ Agree } & \multicolumn{2}{c|}{ Disagree } \\
\hline & $\mathbf{n}$ & $\%$ & $\mathbf{n}$ & $\%$ \\
\hline 1. Clinicians should engage in research & 71 & 81.6 & 15 & 17.3 \\
\hline 2. Research would enhance clinical practice & 79 & 90.8 & 8 & 9.2 \\
\hline 3. Research is for academics only & 30 & 34.5 & 57 & 65.5 \\
\hline 4. Clinicians should carry out research & 37 & 42.5 & 50 & 57.5 \\
\hline $\begin{array}{l}\text { 5. Research reports use language different } \\
\text { from routine clinical language }\end{array}$ & 49 & 56.3 & 38 & 43.7 \\
\hline
\end{tabular}

Table 3: Factors Militating Against Research

\begin{tabular}{|l|c|c|c|c|}
\hline & \multicolumn{2}{|c|}{ Agree } & \multicolumn{2}{c|}{ Disagree } \\
\hline & $\mathbf{n}$ & $\%$ & $\mathbf{n}$ & $\%$ \\
\hline 1. Lack of equipment & 62 & 71.3 & 25 & 28.7 \\
\hline 2. Poor library facilities & 70 & 80.4 & 17 & 19.6 \\
\hline 3. Lack of research facilities & 65 & 74.7 & 22 & 25.3 \\
\hline 4. Time constraints & 75 & 86.2 & 12 & 13.8 \\
\hline 5. Lack of pre-requisite training & 39 & 44.8 & 48 & 55.2 \\
\hline
\end{tabular}

years. Twenty-eight (32.2\%) had higher degrees (Postgraduate diploma, PG certificate and Master's degree). The research activities of the clinicians are shown in Table 1. The data obtained showed that $41.4 \%$ of the clinicians submitted dissertations in partial fulfillment of the requirements for their basic physiotherapy degree. Only $39.1 \%$ of them had ever carried out any research work since basic qualification and $6.9 \%$ had publications in scientific journals. Although $86.2 \%$ of our respondents claimed that reading professional journals enhanced their clinical practice, only $39.1 \%$ were regularly subscribing to professional journals. Table 2 summarizes the belief about research, and attitude towards research activities among the respondents. The various militating factors against research are given in Table 3.

\section{DISCUSSION}

Research is important in widening the underlying and unique knowledge base of a profession, demonstrating the effectiveness and scientific merit of the knowledge base, and in developing a more distinct identify for the profession (Robertson, 1995). This study has shown the attitude of Kuwait-based CPTs towards research, and the level of their participation in research activities. 
Although not all the questionnaire forms distributed to the sampled CPTs were retrieved, the number returned and completed gave a return rate of $93 \%$ constituting about one third of the total number of CPTs in all Ministry of Health Hospitals in Kuwait (Office of Physiotherapy Affairs, 2001). The results showed that years of post-basic qualification experience of the respondents varied highly (three to 35 years) and this implies a well mixed sample in terms of level of experience. Only a third had a post-basic degree certificate or diploma. This may be a reflection of how much opportunity for postgraduate training was available to the CPTs surveyed. It could also be an indication of their lack of interest in pursing higher degrees, especially in situations where academic qualification(s) may not necessarily translate to better condition of services, or promotions. More than half of those who claimed to have submitted dissertations at the basic qualification levels had engaged in research activities. It was clear therefore that undergraduate research work didn't translate to a post-qualification research habit in the respondents surveyed. The percentage of respondents with publications in professional journals was very low. The non-availability of local journals where research work could be published may be a contributing factor. The majority of the respondents were of the opinion that CPTs should engage in research activities, as these would enhance clinical practice. Despite this belief only a small percentage had every engaged in research. This is in line with the observation of Crosbie (2000), that despite the recog nition for the need of scientific evidence to support our practice, relatively little is done to support research. He concluded that CPTs should see research as a duty and a legitimate part of clinical practice, rather than a threat to ward off. Time constraints, poor library facilities, lack of research facilities and equipment were identified as hindrances to participation in research. Some of the CPTs also believed that if taken through research training, they would research effectively. Lack of research training (Lobindo Wood and Haben, 1986) and poor access to library facilities (Sheehan, 1986) have been documented in studies involving the nursing profession. Time constraint as a hindrance to research could be an indication of a large clinical workload or a problem with time management on the part of the surveyed CPTs. Neither of these reasons could be confirmed from the results of this study. From the results obtained in this study, it could be concluded that there is a low participation level in research activities amongst the Kuwait-based CPTs surveyed. It was also observed that a significantly low proportion of therapists in this study had publications in scientific and professional journals.

\section{RECOMMENDATIONS}

a) Clinical physical therapists in Kuwait should increase their research activities and publish their research findings. This could be enhanced by collaboration between the university faculty members and CPTs in Kuwait.

b) Necessary facilities such as library materials, research funding, research equipment and in-service research training should be made available to the CPTs in order to enhance their research practice.

\section{REFERENCES}

Basmajian J V 1977 Professional survival: The research role in Physical Therapy. Physical Therapy 57(3): 283 - 285

Crosbie J 2000 Physiotherapy research: A retrospective look at the future. Australian Journal of Physiotherapy 46: 159 - 164

Currier D P 1979 Elements of Research in Physiotherapy. Baltimore, Williams and Wilkins Company.

Fowler (Jr) W M 1969 Physical therapy and Research. Physical Therapy 49(9): 977 - 982

Kuwait Office of Physiotherapy Affairs 2001 Data on file

Lobindo-Wood G, Haber J 1986 Nursing Research: Critical appraisal and utilization. CV Mosby, Toronto
Parry A 1994 The golden heresy of truth. Physiotherapy 80 (A): 77A - 78A

Power B A, Knapp T R 1995 A Dictionary of Nursing Theory Research. 2nd edition, Sage, Thousand Oaks, California

Robertson V J 1995 Research and the cumulation of knowledge in Physical Therapy. Physical Therapy 75(3): 223 - 236

Rogers S 1976 A role for Physiotherapists in research. Physiotherapy 62(4): 127-128

Sheehan J 1986 Nursing research in Britain. The State of the art. Nurse Education Today 6: $3-10$

Smeitzer, Hinshaw A 1986 Research: Clinical integration for excellent patient care. Nursing Management 19: 38 - 40 